\title{
NEW DIRECTIONS IN NATIONAL EDUCATION POLICYMAKING: STUDENT CAREER PLANS IN INTERNATIONAL ACHIEVEMENT STUDIES
}

\author{
Joanna Sikora and Lawrence J. Saha
}

\begin{abstract}
Our first goal is to discuss new information for national policymaking which may arise from the analyses of international achievement study data. The second is to illustrate this potential by exploring determinants of students' career plans in a cross-national perspective. Using neoinstitutionalism as our theoretical framework, we propose that the influence of a global educational ideology encourages high levels of occupational ambitions among students. This is particularly the case in countries where the transfer of this ideology is supported by the reception of aid for education, where economic prosperity is at modest levels but the service sector employment is expanding. To explore this proposition, we analyze students' occupational expectations using the 2006 PISA surveys from 49 countries. We account for a broad range of possible determinants by estimating three-level hierarchical models in which students are clustered in schools and schools within countries. We find that at
\end{abstract}

\footnotetext{
The Impact of International Achievement Studies on National Education Policymaking International Perspectives on Education and Society, Volume 13, 83-115

Copyright (C) 2010 by Emerald Group Publishing Limited

All rights of reproduction in any form reserved

ISSN: 1479-3679/doi:10.1108/S1479-3679(2010)0000013007
} 
individual and school levels, ambition is positively correlated with economic and noneconomic resources. In contrast, students in poorer countries, where secondary education is not yet universally accessible, tend to be more ambitious. The global educational ideology, indicated by the reception of education-related aid, is associated with student career optimism, while students in affluent nations with less economic inequality have modest occupational plans. In addition, the rate of sector service expansion is positively related to high levels of ambition. These patterns hold even after we control for cross-national variation in the extent to which PISA respondents represent populations of 15-year-olds in their countries.

\section{INTRODUCTION}

The purpose of our chapter is to identify new directions through which international achievement studies can contribute to national policymaking. Although we use data from the Programme for International Student Assessment (PISA) which focus on academic achievement, our study focuses on a nonacademic outcome, namely student occupational expectations. Although achievement scores are central to the PISA project, a growing understanding of their significance will be found in the nonachievement context variables. This is due to the unprecedented "... wealth of contextual background information from participating students and their homes, teachers and schools" (Rutkowski, Gonzalez, Joncas, \& von Davier, 2010, p. 142) in the PISA variables. These data make possible more comprehensive contextual analyses of the roles that micro- and macro-level opportunity structures and subjective perceptions play in students' educational outcomes. Because of this perspective, we study the determinants of the occupational plans of PISA adolescents which have policy relevance not only for the educational and occupational attainments of young people, but also for career counselling and market-planning policies.

In addition to the study of the relationships between educational and occupational attainments, the analysis of young people's occupational expectations can reveal both local and global forces which affect youth career plans. The latter represents important changes to the general cultural milieu which is introduced by the spread of a global educational ideology (Kamens \& McNeely, 2010, p. 10). The impact of globalization transforms the economic outlooks of nation states which often facilitate rather than resist its progress, and thus strive to produce an appropriate labor force to 
support their expanding economy. The growth of economies goes hand in hand with the expansion of education systems, and the new discourses and imageries of the global ideology then shape the individual goals of youth. Therefore, the expectations of young people are affected not only by individual preferences for the intrinsic rewards of particular jobs, and by family and school environments, but also by the knowledge of labor market opportunities. The transnational educational ideology which emphasizes equality of opportunity, the right to quality education, and connectedness to international labor markets is arguably an important context for youth career formation. Our goal in this chapter is to highlight the impact of this broad context on cross-national differences in adolescent occupational plans.

We open this chapter with a literature review which focuses on the neoinstitutionalist and status attainment theories as frameworks for understanding the complex and dynamic configurations of influences which shape students' plans. We argue that in addition to individual and school characteristics, it is necessary to include cross-national variations in the linkage to global educational ideologies. These cross-national variations also include the characteristics of national education systems and the economic conditions within nation states, for these also may affect student ambitions, possibly in opposite directions. Our literature review focuses on the neo-institutionalist and status attainment theories as frameworks for understanding these complex and dynamic configurations of influences which shape students' plans. We then proceed to the empirical analyses of students' occupational expectations in the PISA countries. Our analysis includes a discussion of some potential pitfalls of investigations of the type presented here, such as the truncated sample of PISA countries and missing data. We also consider issues related to the differences in secondary school participation rates across countries and their implications for cross-country comparisons. In conclusion, we discuss the value of our results for policymaking and for the future problems and promises of cross-national research on the "context" variables in achievement studies.

We are aware that the use of PISA data for our analyses may raise questions for some readers. PISA represents a relatively recent development in a string of international achievement studies which include the International Project for the Evaluation of Educational Achievement (IEA), the Trends in International Mathematics and Science Study (TIMSS), and Progress in International Reading Literacy Study (PIRLS). Because PISA is sponsored and in part funded by the OECD, it has the resources and legitimacy to dominate policymaking in an unprecedented manner. 
Unlike previous international achievement surveys, the PISA data clearly provide an opportunity for far more than simple comparisons of country educational performances. No other survey has approached the study of school knowledge based on the perceived needs of adult success in modern society. This makes the PISA surveys potentially more sensitive, compared to previous international surveys, to the awareness or experience of an institutionalizing or globalizing impact which was never widely discussed in the context of these other studies. Our study is the first to ask whether an institutionalized world education culture can be assumed to involve a dominant imagery of desirable careers, for example, a professional career which is both a product and an agent of educational expansion and the international isomorphism in educational practices and ideologies. To investigate the presumed influence of global-level effects, we use hierarchical linear modeling. This procedure allows us to analyze the factors which influence student occupational expectations at the individual, school, and country levels.

The key questions we address are as follows: (1) Can we learn anything new about the determinants of youth plans from three level cross-national analyses in which between-country variation complements the same set of factors in individual country-by-country comparisons? In other words, do three-level analyses, in which students are clustered in schools, and schools are clustered in countries, provide new information about the wider global contexts within which adolescents form their occupational plans? and (2) Can this knowledge inform educational equity and vocational counselling policies by incorporating the influence of local and global ideologies on students' career ambitions?

\section{PRIOR RESEARCH AND OUR THEORETICAL FRAMEWORK}

Before a global perspective in the study of student career plans emerged, the occupational expectations of students were investigated primarily as individual phenomena by developmental psychologists whose interest lay in career counselling. Within sociology, career plans have also been studied but have been related to social mobility within and between generations (Musgrave, 1967; Turner, 1964). In the latter tradition, it was found that an advantaged family background coupled with high levels of achievement raised educational aspirations and expectations which, in time, boosted 
occupational attainments. These positive correlations between advantage and ambition were found both at the individual and the school levels. Initially, there was some conceptual ambiguity between career aspirations and expectations. The distinction between these two concepts was recognized early because of the awareness that the former measured life plans which were relatively unaffected by perceived social restraints, whereas the second took them into account (Caro \& Pihlblad, 1965; Desoran, 1977/1978; Empey, 1956; Han, 1969; Saha, 1983, 1997). Later, expectations defined in this way were found to be better predictors of actual attainments than aspirations (Goyette, 2008) and thus the PISA questionnaires have included only the measure of students' expectations.

Despite the long-standing consensus that the vocational preferences of students are driven by individual interests, perceived intrinsic rewards of particular careers, and personality types (Brown, 2002; Holland, 1997), psychologists recognize that students' career expectations are not formed in a social vacuum. This is consistent with status attainment research within sociology which emphasizes the role of economic and cultural capital in the family of origin, and the role of structural barriers within institutional systems, as crucial determinants of students' ambitions. The researchers in both traditions found that career plans are shaped by family backgrounds (including economic, social, and cultural capital), community factors, peer groups, students' work experience, and local labor market conditions (Gottfredson, 2002; Johnson \& Mortimer, 2002). By and large, social advantage in various forms raises the levels of ambition, although under some circumstances some disadvantaged groups or minorities display very high levels of expectations as shown by both psychological and sociological research (Feliciano \& Rumbaut, 2005; Helwig, 2008; Looker \& McNutt, 1989; Rajewski, 1996; Rindfuss, Cooksey, \& Sutterlin, 1999; Saha, 1983; Saha \& Sikora, 2008). This latter point is important because occupational plans have been found to be especially good predictors of later occupational attainments, not only for older generations but also for recent cohorts of high school students (Croll, 2008; Rindfuss et al., 1999). Recent research in Australia has confirmed this relationship, even after the educational plans of youth and their actual university completion had been statistically controlled (Sikora \& Saha, 2010).

Earlier, concerns that youth plans were only "flights of fancy," fleeting, and randomly fluctuating (Alexander \& Cook, 1979) have been shown to be unfounded. In fact, although upon the completion of studies graduates rarely work in the exact occupations desired in high school, students who can articulate specific and ambitious goals at that time are more likely to 
succeed in early entry to high-status occupations (Croll, 2008, Rindfuss et al., 1999). This higher likelihood is net of academic performance, family SES and a host of other influences. To complement and extend these findings, we argue that the educational ideology which comes packaged with the imagery of highly skilled and well rewarded employment typical for increasingly service-oriented economies has its own capacity to stimulate very ambitious plans among students, particularly in countries where the prevalence of such employment is yet to become a reality. The impact of this ideology does not eradicate the effects of individual differences and the differences in school environments on students' expectations. Moreover, we contend that its effects depend also on economic and social conditions in particular countries. Until education systems become more homogenous across countries, returns to education will remain higher in poorer, less developed societies which experience more inequality (Psacharopoulos \& Patrinos, 2004). This, coupled with a rapid expansion of educational systems and the growth of service employment within these countries, is likely to trigger high levels of ambition among youth.

\section{THEORETICAL FRAMEWORK AND THREE LEVELS OF INFLUENCES ON STUDENTS' CAREER PLANS}

We employ two theoretical perspectives to examine three contextual levels in which students formulate their vocational plans. Our first perspective is the institutional approach developed by Meyer and his colleagues (Benevot, 1997; Meyer, Ramirez, Rubinson, \& Boli-Bennett, 1977; Schofer \& Meyer, 2005), which informs our macro-level analysis. At the same time, we incorporate developments within the status attainment perspective, which informs our analyses of gender, academic ability, student family background, and school characteristics. These latter are our control variables.

The institutional theoretical approach focuses on the global expansion of educational systems, on the institutional links between education and other social institutions, and finally on the impact of mass education on other institutional arrangements in society (Benevot, 1997). Institutional theory is particularly well-suited to guide the study of attainment processes at the cross-national level because it emphasizes the impact of global pressures on local educational systems. This perspective explains the increasing isomorphism of national education systems, driven by global educational expansion and progressive standardization, and by universal educational 
values supported by supranational organizations like UNESCO and the World Bank. Yet it also allows for cross-country variation in responses to the standard and uniform ideologies which are influenced by local cultural and economic conditions within nation states.

Suda (1979) contended that as education expands in developing countries, the perceptions of life chances are raised unduly, resulting in what some have called "the diploma disease" (Dore, 1976). Moreover, as Irizarry (1980) pointed out, under the contradictions of capitalist development in these countries, ambitions are raised but with limited possibilities for their fulfillment. With the expansion of educational systems and the globalization of labor markets, what seemed previously to be unduly ambitious expectations, particularly among youth in less developed countries, becomes part of the worldwide cultural milieu dominated by the assumptions of equal rights to education for all and, likewise, equal access to highly skilled and well rewarded employment (Wiseman \& Baker, 2006).

In addition to the variation in economic structures of opportunity, and, as we argue, the ideological influences of a global culture of education, the status attainment theory postulates that preferences of students are affected by the features of families, schools, and national school systems. For instance, the most recent studies find that students form "more realistic" and thus less ambitious educational expectations in highly stratified systems, which rely on early specialization and tracking (Buchmann \& Dalton, 2002; Buchmann \& Park, 2009). Similarly, Mortimer and Krüger (2000) found that, with respect to career destinations, the differentiation of educational institutions served to maintain stratified pathways. Unequal access to university-oriented academic pathways, or even to higher-level secondary schooling, is the key factor determining not only educational but also occupational attainment. This is why, in our analyses, we control for the degree of educational system differentiation, rates of participation in secondary education, and the prevalence of tertiary educated workers among the youngest adults. However, none of these measures directly captures the influence of global educational ideology. To address this issue, we employ data about countries' access to aid for education. Youth in countries which receive aid to expand and improve their education systems are direct recipients of the key messages contained in the equity discourse of global educational ideologies. Moreover, they live in economic conditions which may facilitate optimism about prospects of upward mobility associated with development. We argue that it is this change in both educational ideologies and economic conditions that fosters high levels of optimism in students' career expectations. 
Following from the points discussed above, we next develop the hypotheses which will guide our analysis.

\section{HYPOTHESES}

The direct link to educational expansion programs, which propagate ideas of equality, citizens' rights, and economic progress, should stimulate ambitious career plans even in countries in which current labor markets cannot accommodate echelons of highly skilled professionals. Therefore, we expect that students in countries which receive educational aid will more likely be optimistic in their career expectations despite the less favorable economic conditions in their local labor markets (H1).

However, we also expect that this optimism is not only stimulated by the connectedness to global educational ideologies but also to the pace of expansion in local labor markets. Therefore, we propose that in countries where the service sector has grown rapidly in recent years, students will expect professional and managerial employment despite low levels of economic prosperity and pervasive economic inequalities (H2). To account for forces which curb and moderate student optimism, and in line with prior research on stratified education systems, we expect lower levels of expectations in countries where tracking and segregation of students start at or before the age of $15(\mathrm{H} 3)$. We control our analyses for rates of participation in secondary education to keep in check the possibility that the apparent higher levels of ambitions in poorer countries result from the fact that only the more determined and affluent students are at school at the age of 15 . Finally, we also control for the proportion of tertiary educated among the youngest workers, because high levels of tertiary attainment may boost the expectations for professional employment among adolescents. These three hypotheses are tested after controlling not only for access to secondary and tertiary education but also for an association between parents' socioeconomic status and students' career goals, their gender, and their academic ability.

Schools in which students' parents have higher occupational standing are known to be conducive to higher educational attainment. This is because school communities, which consist of many skilled, affluent, and welleducated parents, utilize not only material but also social resources to benefit and advance their students. Therefore, we also control for schools' average parents' SES, selective admission policies at the school level which screen out average and below average students, and urban location, all of which are likely to be associated with more ambitious occupational plans. 


\section{DATA, MEASUREMENT, AND METHODS}

To test these hypotheses, we use the most recent round of the OECD's PISA survey, conducted in 2006 in over 50 countries. Our dependent variable is derived from a single question which has been asked in most PISA surveys.

What kind of job do you expect to have when you are about 30 years old?

Write the job title:

Although a measure based on a single question can be seen as potentially problematic, particularly in light of concerns expressed about the variability of adolescents' plans over time (Rindfuss et al., 1999, p. 231), this practice is a standard form of collecting occupational data in surveys. Moreover, research in Australia indicates that, while particular variability in occupational titles desired by teenagers vary over time, their preferences in terms of occupational status are significantly more stable (Sikora \& Saha, 2010). Although PISA participation continues to be dominated by OECD countries, the presence of some "lower-middle income" countries, using the World Bank terminology, with varying levels of economic prosperity, inequality and the receipt of international aid for education programs, makes the analysis of these data suitable for our research questions.

\section{Measurement}

The PISA occupational data, including students' career expectations, was initially coded to ISCO-88, that is, the International Standard Classification of Occupations. These codes then were recoded into the ISEI index of occupational prestige (Ganzeboom \& Treiman, 1996), which, as a measure of occupational expectation, is our dependent variable. ISEI scores range from 10 to 90, with the lowest values denoting unskilled labor and the highest allocated to highly specialized professions, such as neurosurgeons or judges in courts of law.

In this sample of countries, various aspects of institutional contexts are strongly interrelated (see Appendix Table A2 for the full correlation matrix for country-level variables). Therefore, we use an index to convey the information about GDP per capita and the proportion of labor force employed in the service sector. Our modeling strategy follows three steps.

First, we assess the impact of our measure of connectedness to the global educational ideology, namely the reception of education-related aid. Nations which received such aid are coded 1 and the rest are coded 0 . 
Other controls comprise secondary school net enrolment rates, the proportion of people aged between 25 and 34 years who completed tertiary education (defined as ISCED level 5a or 6), and the number of schools or distinct educational programs available to 15 -year-olds within each country. The last variable is our indicator of the differentiation within the school systems.

In the second step, we focus on the economic characteristics of countries as follows: (1) the index of GDP per capita and the share of service employment expressed as ratios to the USA figures and then averaged; (2) the GINI index of economic inequality; and (3) the expansion rate of the service sector. Finally in the third step, we enter all predictors at the country level. These predictors have been sourced from World Bank Development Indicators, UNESCO, and International Labour Office's online databases, complemented with several other sources. The details are provided in the appendix.

At the school level, we control for (1) parents' SES averaged within schools, which identifies schools with higher proportions of students from privileged backgrounds; (2) selective admission based on academic achievement (coded 0 for schools that do not have such a policy and 1 for those that do); and (3) the size of town in which each school is located. In a preliminary analysis, we also included an indicator of the school's autonomy in determining the curriculum, but this variable turned out to be insignificant and thus was omitted from later analyses.

At the individual level, we include gender and parents' socioeconomic status, created from the information on mother and father's averaged ISEI scores, and averaged years of schooling completed. Educational levels were recoded into years using the template provided by the 2003 PISA manual (OECD, 2005a). Education and occupation contribute equally to our measure of parents' SES. Following prior research based on the PISA data (Buchmann and Park, 2009), we averaged five plausible values indicating reading performance to create a control variable indicating prior academic achievement, as the actual data on prior academic achievement are not available. We also control for students' participation in either vocationally or prevocationally oriented programs. This is crucial to account for the possibility that, as in Poland before and after the educational reform first initiated in 1999 and implemented over the next few years, PISA may have been administered to students before or just after the first transition which distributes students into academic versus vocational streams. The timing of such a transition may significantly affect the likelihood of forming concrete occupational plans. 


\section{Method}

To model occupational expectations, we employ random intercept ${ }^{1}$ threelevel linear models, as available in HLM version 6.08, in which students are clustered in schools and schools are clustered in countries, as in Eq. (1).

$$
\begin{aligned}
\text { Expected_Occupation }_{i}= & \text { constant }_{i j k}+\text { Recipient_of Aid_to_Education }_{k} \\
& + \text { Number_of_School_Programs }_{k} \\
& + \text { Percentage_of_25-34_years_old_Tertiary_Educated }_{k} \\
& + \text { Secondary_School_Participation_Rate }_{k} \\
& + \text { Gini }_{k}+\text { Index of_GDP_\&_ServiceEmployment }_{k} \\
& + \text { Growth_of_Service_Sector_1997-2004 }_{k} \\
& + \text { Average_Parents'SSES_in_school }_{j k} \\
& + \text { Size_of_town }_{j k}+\text { Selective_admission }_{j k} \\
& + \text { Male }_{i j k}+\text { Parents'_SES }_{i j k}+\text { Reading_score }_{i j k} \\
& + \text { Vocational_Program }_{i j k}+v 0_{k}+u 0_{j k}+e 0_{i j k}
\end{aligned}
$$

All multivariate analyses are weighted by the student population weight, and a country factor which ensures that each country contributes equally to the analysis (OECD, 2008a). As we rely on linear models which are sensitive to departures from normality, all the analyses have been performed with robust standard errors. The predictors in our models are centered around the overall mean and thus model coefficients should be interpreted as deviations from the grand mean.

\section{Missing data}

As in all data sets, PISA variables have some missing values. Of particular concern are missing values on the dependent variable. Occupational expectation is a variable which is subject to higher levels of missing data than educational plans (Table A1). This is partly due to the fact that some students find it harder to name their expected occupation and therefore give invalid or uncodable responses such as "anything that pays well." But many students do not have clear occupational plans at 15 years of age (White, 2007). Prior research has found that students with lower levels of academic achievement are more likely to skip this question or give uncodable answers 
(Sikora \& Saha, 2009). Therefore, cross-national comparisons of top achievers might be a better strategy when comparing occupational plans because imputing occupational expectations would introduce significant bias (Marks, 2010). This is one of the reasons why we estimate our models for the whole sample and then again for a top achievers subsample. To reduce the loss of information on independent variables, we imputed some data at the individual level for independent variables only. The results from analyses with imputed variables were not substantively different from those obtained without imputations.

\section{RESULTS}

Before we proceed to the analyses of the impact that global educational ideology has on career plans, we first examine the pattern of average ambitions in the context of national economic differences. In countries with higher levels of economic prosperity and lower economic inequality, the average occupational expectations of students tend to be less ambitious. We employ the Gini index of inequality as an indicator of the economic differences between countries, and Fig. 1 illustrates this relationship for the 2006 data.

In 2006, students in South American countries with high levels of inequality tended to report the most ambitious career plans. Equally ambitious were young Jordanians, Tunisians, and students from Azerbaijan whose economies rank lower on the Gini index. At the other end of the inequality spectrum, average occupational expectations of students in the Scandinavian nations, Japan, the Czech Republic, and Slovakia were significantly more modest in terms of their status. However, the average status of future employment is not predicted perfectly by overall levels of economic inequality and we note a number of outliers. First, countries in which students are more modest in their occupational ambitions than their level of inequality would indicate are the developed nations with highly differentiated education systems, namely Germany, Austria, and particularly Switzerland, which is an outlier in Fig. 1. Conversely, students in Iceland, Bulgaria, and Kyrgyzstan report much higher expectations than what is implied by the Gini index income differentials in their country. Overall, despite the identified outliers, the relationship between within country income inequality and levels of occupational expectations appears positive and approximately linear.

In addition to the mean estimates in Fig. 1, and those found in Table A1, Table 1 provides more detail about the distribution of occupational 


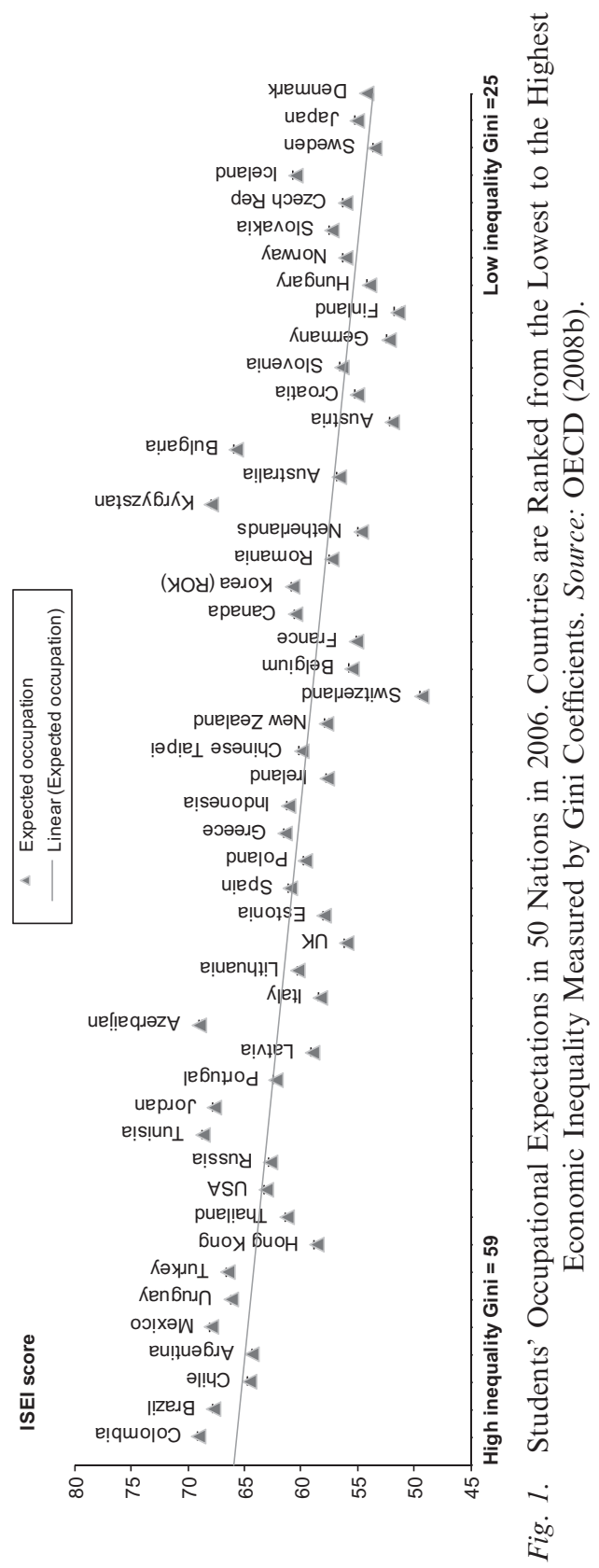




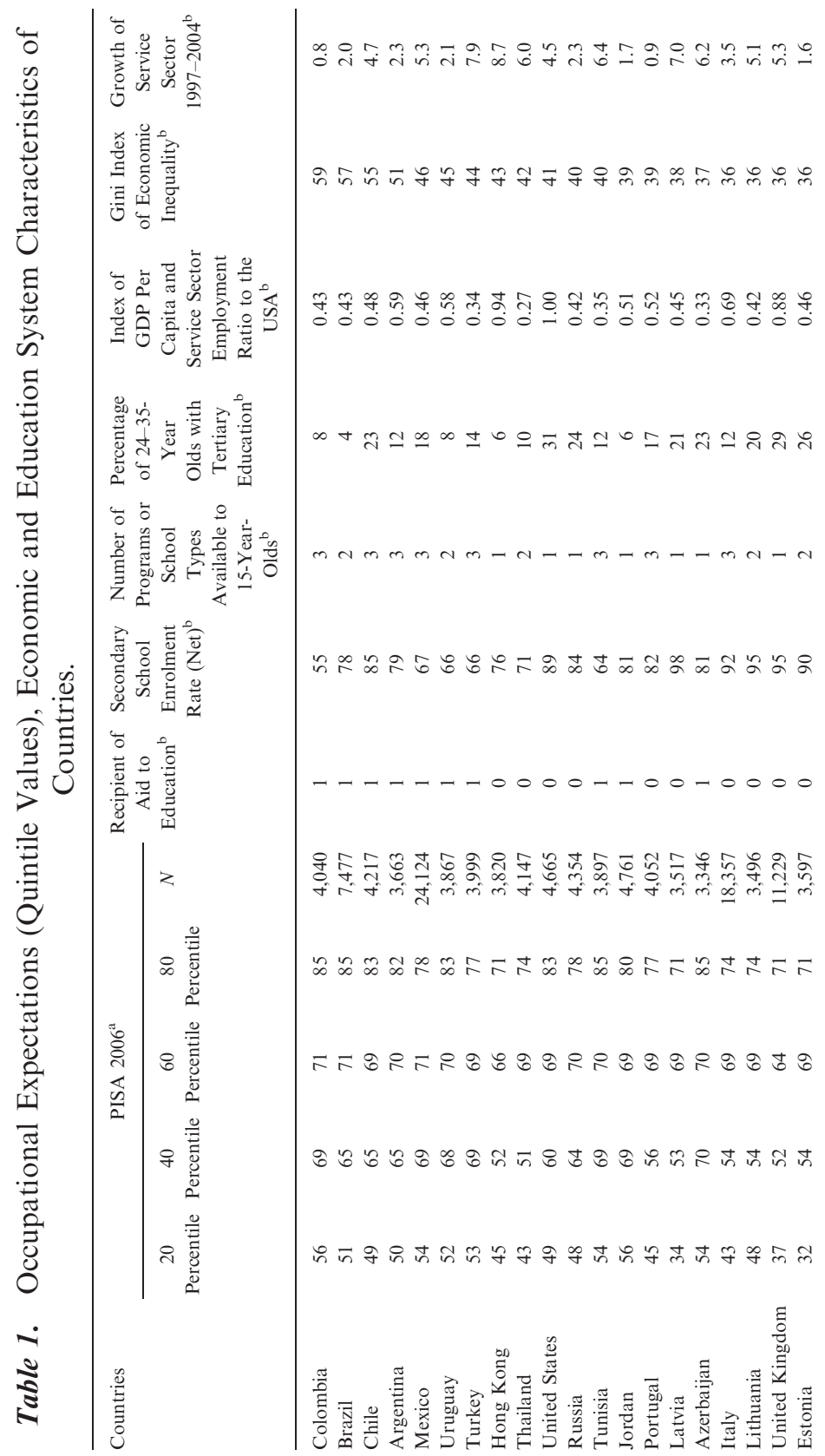




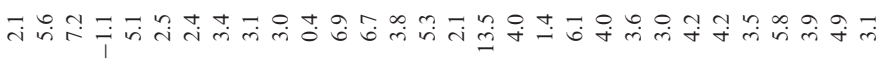

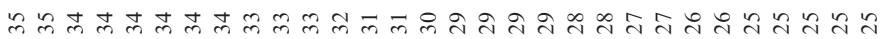

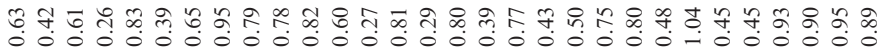
นู่

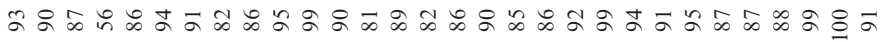
$000-0-00000000-000-1-0000000000$

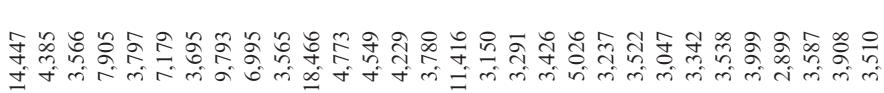

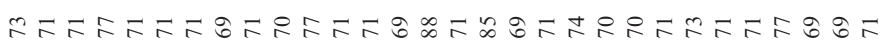

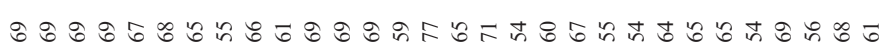

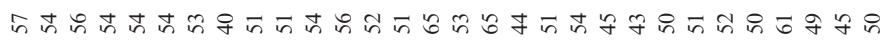

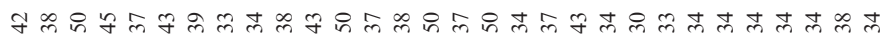

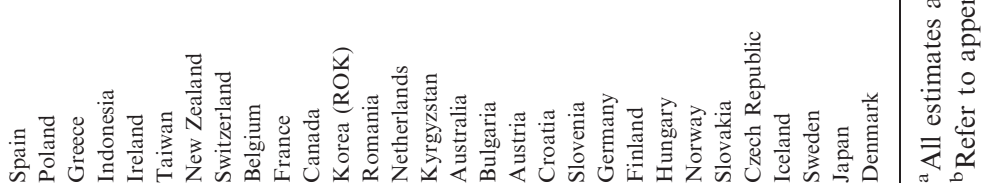


ambition among students in particular countries. We compare quintile values in all surveys in Table 1, in which countries have been sorted by the descending value of the Gini coefficient. The pattern that emerges can be best described as approximately equal distances between the 20th and the 80th percentile of the distributions. In most countries, this distance is approximately about 35 ISEI points. However, in poorer countries characterized by more economic inequality, students' preferences are in greater part focused on professional destinations. If we recall that ISEI scores of 65 and higher denote mostly professional jobs, the distribution of preferences in Brazil, which ranges from 51 to 85, is indicative of much higher status expected by students than the range of Germany, Sweden, Norway, and Finland, with quintile values between the mid-30s and 70s. The plans of students in nations where school participation rates are high and inequality is lower are less concentrated on highly skilled professional destinations.

This opens the possibility that the differences between students can be due primarily to the fact that the populations of students in these countries are not comparable in terms of the representativeness of relevant student age groups. If we make a plausible assumption that those students who leave the school system before the PISA data are collected, come from lower SES backgrounds or are less academically successful, then the PISA data may represent two different populations. In countries where all adolescents progress to upper secondary education, we have a good representation of the whole relevant age group, but in other countries, where not all youth are in secondary school, we have only information from elite students. To gain a better insight into this possibility, we estimate our multivariate models for all students and the elite students. Let us begin with the presentation of the results for all the students who gave valid responses.

\section{MULTIVARIATE ANALYSES}

As our first hypothesis predicted, countries which receive international aid to expand and improve their education systems have students whose career ambitions are, on average, significantly higher than elsewhere (Table 2). This is the case when we control for various features of educational systems, but importantly even after we control for the country's level of GDP per capita, service sector employment, inequality (indicated by the Gini index) and also the rate of expansion of employment in the service sector. 
Table 2. Occupational Expectations: Total Sample.

\begin{tabular}{|c|c|c|c|c|c|c|}
\hline & \multicolumn{2}{|c|}{ Model 1} & \multicolumn{2}{|c|}{ Model 2} & \multicolumn{2}{|c|}{ Model 3} \\
\hline & Coefficient & $\begin{array}{l}\text { Standard } \\
\text { error }\end{array}$ & Coefficient & $\begin{array}{l}\text { Standard } \\
\text { error }\end{array}$ & Coefficient & $\begin{array}{l}\text { Standar } \\
\text { error }\end{array}$ \\
\hline \multicolumn{7}{|l|}{ Fixed effects } \\
\hline \multicolumn{7}{|l|}{ Country characteristics } \\
\hline $\begin{array}{l}\text { Country receives } \\
\text { education-related } \\
\text { aid }\end{array}$ & $8.94^{* *}$ & 1.93 & - & & $7.20^{* *}$ & 1.84 \\
\hline $\begin{array}{l}\text { Secondary school net } \\
\text { enrollment rate }\end{array}$ & $-0.42^{* *}$ & 0.10 & - & & $-0.28 * *$ & 0.10 \\
\hline $\begin{array}{l}\text { Number of school } \\
\text { types available to } \\
\text { 15-year-olds }\end{array}$ & -0.96 & 0.68 & - & & -0.82 & 0.55 \\
\hline $\begin{array}{l}\text { Percentage of 25-34- } \\
\text { year-olds with } \\
\text { tertiary education }\end{array}$ & -0.03 & 0.12 & - & & -0.05 & 0.08 \\
\hline $\begin{array}{l}\text { Index of GDP per } \\
\text { capita and service } \\
\text { employment ratio } \\
\text { to USA }\end{array}$ & - & & $-20.06^{* *}$ & 3.78 & $-11.90^{* *}$ & 3.21 \\
\hline Gini coefficient & - & & $0.51^{* *}$ & 0.11 & 0.14 & 0.12 \\
\hline $\begin{array}{l}\text { Growth of the service } \\
\text { sector 1997-2004 }\end{array}$ & - & & 0.61 & 0.41 & $0.84^{*}$ & 0.37 \\
\hline \multicolumn{7}{|l|}{ School characteristics } \\
\hline $\begin{array}{l}\text { Parents' SES } \\
\text { averaged by school }\end{array}$ & $1.80^{* *}$ & 0.66 & $1.80 * *$ & 0.66 & $1.82^{*}$ & 0.66 \\
\hline $\begin{array}{l}\text { Selective admission } \\
\text { based on } \\
\text { achievement }\end{array}$ & 1.97 & 1.27 & 1.95 & 1.27 & 1.91 & 1.27 \\
\hline $\begin{array}{l}\text { Size of town } \\
\text { (millions of } \\
\text { inhabitants) }\end{array}$ & 0.27 & 0.74 & 0.28 & 0.74 & 0.26 & 0.74 \\
\hline \multicolumn{7}{|l|}{ Individual characteristics } \\
\hline Male & $-1.32 * *$ & 0.55 & $-1.32^{*}$ & 0.55 & $-1.32^{*}$ & 0.55 \\
\hline $\begin{array}{l}\text { Parents' SES } \\
\text { (education and } \\
\text { ISEI) }\end{array}$ & $2.01^{* *}$ & 0.26 & $2.01^{* *}$ & 0.26 & $2.01^{* *}$ & 0.26 \\
\hline Reading score & $0.06^{* *}$ & 0.00 & $0.06^{* *}$ & 0.00 & $0.06^{* *}$ & 0.01 \\
\hline $\begin{array}{c}\text { Nonnational language } \\
\text { spoken at home }\end{array}$ & $4.88^{* *}$ & 1.00 & $4.88^{* *}$ & 1.00 & $4.88^{* *}$ & 1.00 \\
\hline
\end{tabular}


Table 2. (Continued)

\begin{tabular}{|c|c|c|c|c|c|c|}
\hline & \multicolumn{2}{|c|}{ Model 1} & \multicolumn{2}{|c|}{ Model 2} & \multicolumn{2}{|c|}{ Model 3} \\
\hline & Coefficient & $\begin{array}{l}\text { Standard } \\
\text { error }\end{array}$ & Coefficient & $\begin{array}{l}\text { Standard } \\
\text { error }\end{array}$ & Coefficient & $\begin{array}{l}\text { Standard } \\
\text { error }\end{array}$ \\
\hline $\begin{array}{l}\text { Vocationally oriented } \\
\text { program }\end{array}$ & $-4.98^{* *}$ & 1.06 & $-4.98^{* *}$ & 1.06 & $-4.98^{* *}$ & 1.06 \\
\hline (constant) & $59.02^{* *}$ & 0.80 & $58.79^{* *}$ & 0.85 & $58.78^{* *}$ & 0.61 \\
\hline \multicolumn{7}{|l|}{ Random effects } \\
\hline $\begin{array}{l}\text { Variance at country } \\
\text { level }\end{array}$ & 28.0 & $10 \%$ & 33.1 & $11 \%$ & 18.1 & $7 \%$ \\
\hline $\begin{array}{l}\text { Variance at school } \\
\text { level }\end{array}$ & 127.0 & $44 \%$ & 127.0 & $44 \%$ & 127.0 & $46 \%$ \\
\hline $\begin{array}{l}\text { Variance at student } \\
\text { level }\end{array}$ & 130.9 & $46 \%$ & 130.9 & $45 \%$ & 130.9 & $47 \%$ \\
\hline $\begin{array}{l}\text { Explained variance at } \\
\text { country level }\end{array}$ & $21 \%$ & & $6 \%$ & & $49 \%$ & \\
\hline $\begin{array}{l}\text { Explained variance at } \\
\text { school level }\end{array}$ & $24 \%$ & & $24 \%$ & & $24 \%$ & \\
\hline $\begin{array}{l}\text { Explained variance at } \\
\text { student level }\end{array}$ & $8 \%$ & & $8 \%$ & & $8 \%$ & \\
\hline $\begin{array}{l}\text { Percent total explained } \\
\text { variance }\end{array}$ & $17 \%$ & & $16 \%$ & & $20 \%$ & \\
\hline Number of countries & 49 & & 49 & & 49 & \\
\hline Number of schools & 13,580 & & 13,580 & & 13,580 & \\
\hline Number of students & 281,981 & & 281,981 & & 281,981 & \\
\hline
\end{tabular}

**Statistically different from zero at $p=0.01$, *statistically different from zero at $p=0.05$. All analyses weighted with student population weights adjusted so that each country contributes equally to the analysis.

Receiving aid can be seen as a form of connectedness to the international educational agencies and thus to the ideological packages which they promote. Yet, aid is given primarily to developing countries, so the effects of economic conditions must be controlled for, as they are in Model 3, if the reception of aid is to be conceptualized as an indicator of a strong link to global educational ideology. In Model 1, the coefficient for participation rates in secondary education is negative, which indicates that in countries where some youth are no longer at school at 15 years of age, youth remaining at school expect particularly high levels of occupational attainment. Yet, the difference between more and less selective secondary education systems does not render all other country-level characteristics 
irrelevant. In Model 1, the association between average ambition and highly differentiated education systems, denoted by a number of distinct school programs available to 15 -year-olds, is negative although not statistically significant. Nevertheless, the direction is consistent with findings in other studies of educational expectations (McDaniel, 2010), although we find no strong evidence in support of our third hypothesis. Finally, the prevalence of tertiary education has no discernible effects.

Model 2 considers economic characteristics, that is, countries' level of affluence indicated by the 2004 GDP per capita, combined with the 2004 proportion of the labor force employed in services, economic inequality, and the rate of growth of the service sector. Clearly, it is the youth living in poorer countries, where economic inequality is pervasive, who are particularly keen to enter high-status professional and managerial employment. In contrast to the effects of GDP and service employment, the rate of expansion of the service sector is positively associated with adolescent hopes for professional jobs, as stipulated by our second hypothesis (H2), although this effect is not significant in all models. Nevertheless, the direction of association is consistent with the notion that what fosters high ambitions among youth is less the level of economic development and prevalence of service employment, but rather the rate of growth in the service sector.

Obviously, there is a good deal of intercorrelation between these factors, hence, when seven different measures are entered simultaneously into the model, some effects are cancelled out. However, the reception of financial aid for education, which is associated with various forms of transfer of the global model of education, remains an important indicator of ambitious career expectations among 15-year-old students.

The control variables at school level reveal a strong relationship between school parental SES and occupational ambitions. This relationship is significantly stronger than the predictive power of selective admission, which pre-screens students' academic achievement, and urban residence as indicated by the size of town. Both these latter influences are positive (not shown in Table 2) until controls for average parents' SES within schools are introduced into the models.

In terms of individual variables, our results are consistent with the findings of previous studies. Girls are more oriented toward higher status employment than boys, and parents' socioeconomic position significantly raises students' ambition (McDaniel, 2010; Marks, 2010; Sikora \& Saha, 2009). This effect is separate from the increase provided by academic performance, and this is in line with status attainment theory which predicts separate and complementary effects of parents' background and academic 
achievement on ambition levels. In other words, some students from lower SES backgrounds might be motivated more by their excellent academic performance, whereas students of high SES origin may need little academic success to aim for professional jobs. In either case, an early entry into a vocationally oriented program reduces plans for higher status employment, independently of the other individual-level variables.

The analyses presented in Table 2 highlight the relatively low proportion of variance attributable to cross-national differences for this dependent variable. About $10 \%$ of variance in occupational plans can be attributed to differences between countries. In contrast, approximately $45 \%$ is attributable to differences between schools and another $45 \%$ is due to individuallevel differences. These findings have implications for policymakers in designing and implementing various vocational and nonvocational educational policies. Policymakers need to understand the relative importance of particular factors which differentiate youth occupational ambitions, namely the extent to which relative socioeconomic differences between students, compared to relative differences between school communities and countries, facilitate expectations of high-status careers.

Our analysis indicates that social selection processes affect youth career plans in various ways. Adolescents, whose parents pass on multiple advantages, who are models of high-status employment, and who provide guidance and assistance in navigating educational systems, are the ones who plan for higher status employment. Those students who are successful at school are also more oriented toward the professions. But above and beyond individual differences and school environments, the connectedness to the global ideological package which promotes equal access to high-quality education for all, fosters highly ambitious career plans in youth from less developed countries with high levels of economic inequality.

\section{THE RELATIONSHIP BETWEEN INEQUALITY AND CAREER PLANS: A FUNCTION OF SELECTIVITY?}

Our argument, that it is the impact of global educational ideology coupled with relative economic deprivation and also rapid economic growth that stimulate ambitious career plans among youth, needs another sensitivity test. To provide stronger support for the proposition that cross-country differences in our dependent variable cannot be explained away by unequal access to secondary education, we will replicate our original analysis on a 
subsample of the most academically able, that is, elite students. If, by using a subsample drawn according to ability, the original relationship between country characteristics and occupational expectations does not persist, then we must conclude that differences in participation rates are the primary factor generating cross-country variation in these expectations. On the other hand, if the original relationship persists, then we can conclude with more confidence that macroeconomic and macrosocial factors play a role in shaping youth ambition.

We include students in the top $30 \%$ of the reading score distribution in countries in which $100 \%$ of 15 -year-old students are enrolled in high school. In a country like Mexico, where only $67 \%$ of the students in the relevant age group are enrolled in secondary school, we take $45 \%$ (i.e., $30 / 67$ ) from the top to counterbalance the possible distortion due to systematic variation in participation rates. In Table 3, we present a replication of our earlier multivariate analysis, but this time the sample is restricted to the academically most able "elite" students in all countries.

Overall, the results for the elite students are reasonably close to the patterns, which we found when students with all levels of academic ability were analyzed. The effects of participation rates remain negative and significant, and the association between our measure of connectedness to international educational aid agencies and average expectations persists, although somewhat reduced in terms of point estimates. Thus, we conclude that systematic variation in participation rates does not seem sufficient to explain away country-level variation in student expectations. In fact, country, school, and individual effects are not altered dramatically in the elite subsample analysis.

\section{DISCUSSION}

We began this chapter by posing two questions: (1) Can we improve our knowledge about the determinants of youth occupational plans from three-level cross-national comparisons which make possible the identification of global-level effects as compared to school and individual effects; and (2) Can this knowledge inform educational equity and vocational counselling policies which take into account both local and global effects? In this discussion, we propose an affirmative argument in response to both questions.

In this chapter, our focus has been on the effects of a global educational ideology on student occupational expectations in the context of countries' 
Table 3. Occupational Expectations of Top 30\% of Readers.

\begin{tabular}{|c|c|c|c|c|c|c|}
\hline & \multicolumn{2}{|c|}{ Model 1} & \multicolumn{2}{|c|}{ Model 2} & \multicolumn{2}{|c|}{ Model 3} \\
\hline & Coefficient & $\begin{array}{l}\text { Standard } \\
\text { error }\end{array}$ & Coefficient & $\begin{array}{l}\text { Standard } \\
\text { error }\end{array}$ & Coefficient & $\begin{array}{c}\text { Standar } \\
\text { error }\end{array}$ \\
\hline \multicolumn{7}{|l|}{ Fixed effects } \\
\hline \multicolumn{7}{|l|}{ Country characteristics } \\
\hline $\begin{array}{l}\text { Country receives } \\
\text { education-related } \\
\text { aid }\end{array}$ & $6.19^{* *}$ & 2.21 & - & & $4.46^{*}$ & 2.10 \\
\hline $\begin{array}{l}\text { Secondary school net } \\
\text { enrollment rate }\end{array}$ & $-0.35^{* *}$ & 0.10 & - & & $-0.26^{* *}$ & 0.10 \\
\hline $\begin{array}{l}\text { Number of school } \\
\text { types available to } \\
15 \text {-year-olds }\end{array}$ & -0.43 & 0.50 & - & & -0.40 & 0.47 \\
\hline $\begin{array}{l}\text { Percentage of } 25-34- \\
\text { year-olds with } \\
\text { tertiary education }\end{array}$ & 0.08 & 0.08 & - & & 0.09 & 0.09 \\
\hline $\begin{array}{l}\text { Index of GDP per } \\
\text { capita and service } \\
\text { employment ratio to } \\
\text { USA }\end{array}$ & - & & $-13.53^{* *}$ & 4.47 & $-9.02^{*}$ & 3.40 \\
\hline Gini coefficient & - & & $0.34^{* *}$ & 0.10 & 0.10 & 0.10 \\
\hline $\begin{array}{l}\text { Growth of the service } \\
\text { sector 1997-2004 }\end{array}$ & - & & 0.43 & 0.34 & 0.46 & 0.31 \\
\hline \multicolumn{7}{|l|}{ School characteristics } \\
\hline $\begin{array}{l}\text { Parents' SES averaged } \\
\text { by school }\end{array}$ & $1.90^{* *}$ & 0.58 & $1.90^{* *}$ & 0.58 & $1.93^{* *}$ & 0.58 \\
\hline $\begin{array}{l}\text { Selective admission } \\
\text { based on } \\
\text { achievement }\end{array}$ & 1.30 & 1.20 & 1.28 & 1.21 & 1.23 & 1.21 \\
\hline $\begin{array}{l}\text { Size of town (millions } \\
\text { of inhabitants) }\end{array}$ & $-1.33^{\#}$ & 0.74 & $-1.34^{\#}$ & 0.74 & $-1.36^{\#}$ & 0.74 \\
\hline \multicolumn{7}{|l|}{ Individual characteristics } \\
\hline Male & -0.73 & 0.46 & -0.73 & 0.46 & -0.73 & 0.46 \\
\hline $\begin{array}{l}\text { Parents' SES } \\
\text { (education and } \\
\text { ISEI) }\end{array}$ & $1.55^{* *}$ & 0.21 & $1.55^{* *}$ & 0.21 & $1.55^{* *}$ & 0.21 \\
\hline Reading score & $0.04^{* *}$ & 0.01 & $0.04^{* *}$ & 0.01 & $0.04^{* *}$ & 0.01 \\
\hline $\begin{array}{l}\text { Nonnational language } \\
\text { spoken at home }\end{array}$ & $3.30^{* *}$ & 1.16 & $3.30^{* *}$ & 1.16 & $3.30^{* *}$ & 1.16 \\
\hline
\end{tabular}


Table 3. (Continued)

\begin{tabular}{|c|c|c|c|c|c|c|}
\hline & \multicolumn{2}{|c|}{ Model 1} & \multicolumn{2}{|c|}{ Model 2} & \multicolumn{2}{|c|}{ Model 3} \\
\hline & Coefficient & $\begin{array}{l}\text { Standard } \\
\text { error }\end{array}$ & Coefficient & $\begin{array}{l}\text { Standard } \\
\text { error }\end{array}$ & Coefficient & $\begin{array}{l}\text { Standard } \\
\text { error }\end{array}$ \\
\hline $\begin{array}{l}\text { Vocationally oriented } \\
\text { program }\end{array}$ & $-6.25^{* *}$ & 1.26 & $-6.26^{* *}$ & $* 1.26$ & $-6.27^{* *}$ & 1.26 \\
\hline (constant) & $65.15^{* *}$ & 0.76 & $64.77^{* *}$ & $* \quad 0.76$ & $65.02^{* *}$ & 0.64 \\
\hline \multicolumn{7}{|l|}{ Random effects } \\
\hline $\begin{array}{l}\text { Variance at country } \\
\text { level }\end{array}$ & 22.3 & $9 \%$ & 24.3 & $10 \%$ & 17.8 & $8 \%$ \\
\hline $\begin{array}{l}\text { Variance at school } \\
\text { level }\end{array}$ & 110.5 & $46 \%$ & 110.5 & $45 \%$ & 110.5 & $47 \%$ \\
\hline $\begin{array}{l}\text { Variance at student } \\
\text { level }\end{array}$ & 108.5 & $45 \%$ & 108.5 & $45 \%$ & 108.5 & $46 \%$ \\
\hline $\begin{array}{l}\text { Explained variance } \\
\text { at country level }\end{array}$ & $26 \%$ & & $19 \%$ & & $41 \%$ & \\
\hline $\begin{array}{l}\text { Explained variance } \\
\text { at school level }\end{array}$ & $8 \%$ & & $8 \%$ & & $8 \%$ & \\
\hline $\begin{array}{l}\text { Explained variance } \\
\text { at student level }\end{array}$ & $2 \%$ & & $2 \%$ & & $2 \%$ & \\
\hline $\begin{array}{l}\text { Percent total explained } \\
\text { variance }\end{array}$ & $8 \%$ & & $7 \%$ & & $9 \%$ & \\
\hline Number of countries & 49 & & 49 & & 49 & \\
\hline Number of schools & 11,773 & & 11,773 & & 11,773 & \\
\hline Number of students & 109,273 & & 109,273 & & 109,273 & \\
\hline
\end{tabular}

**Statistically different from zero at $p=0.01,{ }^{*}$ statistically different from zero at $p=0.05$, \# statistically different from zero at $p=0.10$

All analyses weighted with student population weights adjusted so that each country contributes equally to the analysis.

educational systems and economic characteristics. The relevant analytic variables were (1) education-related development aid to recipient countries; (2) the proportion of the relevant age population enrolled in secondary school; (3) the number of program or school types available to 15 -year-old students; (4) the proportion of the population, aged between 25 and 34 years, with a tertiary education; (5) the proportion of the population in service occupations and economic prosperity denoted by GDP per capita; (6) the Gini index, a measure of economic inequality; and (7) the growth in the service sector between 1997 and 2004. 
Youth in countries which are connected to the international education agencies by reception of official aid for education tend to form significantly more ambitious plans than their counterparts in developed economies where all 15 -year-olds are in secondary education. We find that this relationship holds even after economic prosperity, measured by GDP per capita, combined with a measure of service sector employment is taken into account. We consider the reception of aid, after other economic characteristics of countries have been taken into account, to be an indicator of the connectedness to the global educational ideology. Moreover, we find tentative evidence that while the level of economic development is negatively related to average career ambitions of students, the pace of expansion of the service sector fosters high levels of these ambitions. This opens up a new opportunity, or indeed the obligation, to raise the bar in educational and youth career policymaking. Taking account of these third-level effects means that policymaking can now consider more systematically the effect of global-level forces in policies designed to be implemented at the nationstate level. However, three issues will affect the future potential of these "context variable" analyses in international achievement studies. First, the increasing complexity of the nature of evidence will challenge straightforward interpretations of multilevel patterns. Second, the measurement of particular "context variables," which are often less carefully developed than literacy and numeracy scores, might fuel validity debates. Finally, potential selectivity issues, which have been and will continue to affect country-level representativeness in PISA, will continue to pose a challenge to data analysts. These problems will need to be resolved because future PISA surveys will increasingly be used for informing policy relevant not only to achievement levels but also for occupational expectations and thus vocational counselling.

In terms of the relative importance of country and global-level factors, we have found that the largest amount of variance explained in our model occurs at the individual and school levels. However, the significant findings at the third level corresponds to our argument that there is a global, institutionalized cultural force which affects the ways that young students, across countries, view their future careers. To ensure that our results are not brought about by the smaller proportion of youth in schools in the less affluent societies, we repeated the analysis with a subsample of elite students, the top $30 \%$, and found essentially the same results. In other words, our main findings regarding third-level effects are not simply a function of the lower school participation rates of 15 -year-olds in the poorer countries. 
Another equally important finding from our study concerns the rapid change in the service sector of economies. In countries where the service sector grew most between 1997 and 2004 (roughly the period during which our students were undergoing a high level of socialization), the expectations were higher (see Table 2, Model 3). However, the relationship disappeared in the elite analysis. This suggests that for the sample as a whole, the extent of growth in the service sector acted as a stimulus for occupational expectations. The fact that this relationship did not apply for the elite student subsample may indicate that for them, other factors independent of growth, in particular the global ideology and the low-level of development, were more important in driving their ambitions (see Table 3, Model 3).

Although the overall range of countries in the PISA studies remains truncated, and very poor countries are not in the sample, the future expansion of PISA promises that there will be a broader representation from nations with lower levels of development and high levels of inequality. For example, so far there is only one African country in the sample and no representation from China or India, two of the most significant Asian representatives. As more countries join the PISA project, future studies can comment on the findings reported here within the context of a wider range of variation in countries' social conditions and culture.

So far, it is clear that large proportions of young people across all the countries are ambitious with respect to their expected occupational attainments and these levels of ambition are particularly high in countries where education is supported by international organizations and which experience the expansion of not only the education system but also service employment.

Our theoretical perspectives offer plausible interpretations for these findings. The neo-institutional theory argues that educational expansion throughout the world, based on a standard institutionalized model of schooling, has been created as part of world culture and it influences educational systems at the global level. Given that this global model influences education systems, and given the relationship between education and entry into the labor market, it is not unlikely that the occupational expectations of school students are similarly influenced by a world culture of prestigious and desirable occupations, in particular professional-level occupations such as law and medicine. Thus, it is plausible that educational expansion and the spread of global educational ideology is affirmed by and affirms in turn a global culture of prestigious occupations which are known to students everywhere. 
This neo-institutional interpretation is supported by the persistently rising level of educational expansion at the global level. In advanced societies, this expansion is now occurring at the post-secondary level, whereas in poorer countries it continues to occur at the secondary, and even the primary levels. The driving forces in this expansion are the explicit pressures from outside the poorer countries, such as the World Bank, UNESCO, and other global pressures, as well as internal within country forces, such as the expectations of individual country populations. Thus, with the expansion of education comes the expansion of occupational ambitions which are equally influenced by global culture. Indeed, as we have noted earlier in this chapter, the link between education and occupation is strongest in those countries where the participation of students in the education system is lower.

Finally, the notion that there is an institutionalized culture in which young people in most societies participate complements micro sociological explanations of ambitions. When the concept of world culture is combined with theories of youth decision making, we can better understand individual-level decisions.

Probably the most important result from the perspective of policymaking which emerges from this research is that the occupational expectations of young people across the PISA countries are high, and they are most likely higher in less affluent settings in part because of a global culture. Thus, various national policies within a specific country regarding both education and manpower planning have to accept that some forces which impact on the education and career orientations of their young people lie outside of their control. Thus, rather than attempt to hinder this global influence for fear of negative implications of unrealized youth ambitions, policymakers would do best to accept it and try to use it to the advantage of their own policy decisions. This is particularly the case as recent studies, so far limited only to the USA, indicate that high levels of ambitions among youth are on balance more beneficial than detrimental even if ambitions remain unfulfilled (Reynolds \& Baird, 2010).

Ambitious occupational plans can be encouraged through national manpower planning programs, the provision of multiple career streams in the educational system, and training for career or vocational counsellors who give direct advice to students. For all of these programs, our data show that the positive association between a high level of resources and optimistic career plans at individual and school level may be further strengthened or moderated by cultural amalgams which emerge in particular combinations of educational systems and economic conditions. Policymakers might be 
advised that these trends should not be seen as infallible evidence which cannot be altered or contextualized to suit the needs of individual countries. Herein lies the challenge for policymakers. Our study has identified a global phenomenon related to the high occupational ambitions of students, but it remains for the policymakers to take this higher-level effect into account for meeting local needs. Only the cross-national quantitative data sets such as PISA have the possibility of identifying these higher-level global forces, and this is why we contend that this represents a "new direction" for policymaking, which should be pursued as the availability of these data expands.

\section{NOTE}

1. The results from the estimation of two-level random intercept separately in each country, which illustrate the extent to which the assumption of parallel slopes across countries is justified are available upon request from the authors.

\section{REFERENCES}

Alexander, K. L., \& Cook, M. A. (1979). The motivational relevance of educational plans: Questioning the conventional wisdom. Social Psychology Quarterly, 42(3), 202-213.

Benevot, A. (1997). Institutional approach to the study of education. In: L. J. Saha (Ed.), International encyclopedia of the sociology of education (pp. 340-345). Oxford: Pergamon Press.

Brown, D. (Ed.) (2002). Career choice and development (4th ed.). San Francisco: Jossey-Bass.

Buchmann, C., \& Dalton, B. (2002). Interpersonal influences and educational aspirations in 12 countries: The importance of institutional context. Sociology of Education, 75(2), 99-122.

Buchmann, C., \& Park, H. (2009). Stratification and the formation of expectations in highlydifferentiated educational systems. Research on Social Stratification and Mobility, 27(4), 245-267.

Caro, F. G., \& Pihlblad, C. T. (1965). Aspirations and expectations: A re-examination of the bases for social class differences in the occupational orientations of male high school students. Sociology and Social Research, 49, 465-475.

Croll, P. (2008). Occupational choice, socio-economic status and educational attainment: A study of the occupational choices and destinations of young people in the British Household Panel Survey. Research Papers in Education, 23(3), 243-268.

Desoran, R. A. (1977/1978). Educational aspirations: Individual freedom or social injustice? Interchange, 8(3), 72-87.

Dore, R. (1976). The diploma disease: Education, qualification and development. London: Routledge and Kegan Paul.

Empey, L. (1956). Social class and occupational aspiration: A comparison of absolute and relative measurement. American Sociological Review, 21(6), 703-709. 
Feliciano, C., \& Rumbaut, R. G. (2005). Gendered paths: Educational and occupational expectations and outcomes among adult children of immigrants. Ethnic and Racial Studies, 28(6), 1087-1118.

Ganzeboom, H. B. G., \& Treiman, D. J. (1996). Internationally comparable measures of occupational status for the 1988 international standard classification of occupations. Social Science Research, 25, 201-239.

Gottfredson, L. S. (2002). Gottfredson's theory of circumscription, compromise and selfcreation. In: D. Brown (Ed.), Career choice and development (4th ed.). San Francisco: Jossey-Bass.

Goyette, K. (2008). College for some to college for all: Social background, occupational expectations, and educational expectations over time. Social Science Research, 37(2), 461-484

Han, W. S. (1969). Two conflicting themes: Common values versus class differential values. American Sociological Review, 34(October), 679-690.

Helwig, A. A. (2008). From childhood to adulthood: A 15-year longitudinal career development study. The Career Development Quarterly, 57(1), 38.

Holland, J. L. (1997). Making vocational choices: A theory of careers. Odessa, FL: Psychological Assessment Resources.

International Labor Organization (2010). LABORSTA database. Available at http:// laborsta.ilo.org/. Retrieved on 2 August 2010.

Irizarry, R. (1980). Overeducation and unemployment in the third world: The paradoxes of dependent industrialization. Comparative Education Review, 24, 338-352.

Johnson, M. K., \& Mortimer, J. T. (2002). Career choice and development from a sociological perspective. In: D. Brown (Ed.), Career choice and development (4th ed.). San Francisco: Jossey-Bass.

Kamens, D. H., \& McNeely, C. L. (2010). Globalization and the growth of international educational testing and national assessment? Comparative Education Review, $54(1), 5-25$.

Looker, E. D., \& McNutt, K. L. (1989). The effect of occupational aspirations on the educational attainments of males and females. Canadian Journal of Education, 14, 352-367.

Marks, G. N. (2010). Meritocracy, modernization and students' occupational expectations: Cross-national evidence. Research in Social Stratification and Mobility, 28(3), 275-289.

McDaniel, A. (2010). Cross-national gender gaps in educational expectations: The influence of national-level gender ideology and educational systems. Comparative Education Review, 54(1), 27-50.

Meyer, J. W., Ramirez, F. O., Rubinson, R., \& Boli-Bennett, J. (1977). The world education revolution. Sociology of Education, 50, 242-258.

Mortimer, J. T., \& Krüger, H. (2000). Pathways from school to work in Germany and the United States. In: M. T. Hallinan (Ed.), Handbook of the sociology of education (pp. 475-497). New York: Kluwer.

Musgrave, P. M. (1967). Towards a sociological theory of occupational choice. Sociological Review, 15, 33-46.

OECD. (2004). Education at a glance OECD indictators 2004. Paris: OECD Publishing.

OECD. (2005a). PISA 2003 data analysis manual-SPSS users. Available at http://www. oecd.org/pisa

OECD. (2005b). Education at a glance OECD indictators 2005. Paris: OECD Publishing. 
OECD. (2008a). PISA 2006 science competencies for tomorrow's world. Annex A9-SPSS syntax to prepare data files for multilevel regression analysis. Available at http://www.oecd.org/ dataoecd/59/32/39730315.pdf

OECD. (2008b). PISA 2006-machine readable data file. Available at http://pisa2006.acer. edu.au/downloads.php. Retrieved on January 10, 2008.

Psacharopoulos, G., \& Patrinos, H. A. (2004). Returns to investment in education: A further update. Education Economics, 12(2), 111-134.

Rajewski, J. I. (1996). Occupational aspirations and early career choice patterns of adolescents with and without learning disabilities. Learning Disability Quarterly, 19(2), 99-116.

Reynolds, J. R., \& Baird, C. L. (2010). Is there a downside to shooting for the stars? Unrealized educational expectations and symptoms of depression. American Sociological Review, $75(1), 151-172$.

Rindfuss, R. R., Cooksey, E. C., \& Sutterlin, R. L. (1999). Young adult occupational achievement. Early expectations versus behaviour reality. Work and Occupations, 26(2), 220-263.

Rutkowski, L., Gonzalez, E., Joncas, M., \& von Davier, M. (2010). International large-scale assessment data. Educational Researcher, 39(2), 142-151.

Saha, L. J. (1983). Gender, school attainment and occupational plans: Determinants of aspirations and expectations among Australian urban school leavers. Australian Journal of Education, 26(3), 247-265.

Saha, L. J. (1997). Aspirations and expectations of students. In: L. J. Saha (Ed.), International encyclopedia of the sociology of education (pp. 512-517). Oxford: Pergamon Press.

Saha, L. J., \& Sikora, J. (2008). The career aspirations and expectations of school students: From individual to global effects. Education and Society, 26(2), 5-22.

Schofer, E., \& Meyer, J. W. (2005). The worldwide expansion of higher education in the twentieth century. American Sociological Review, 70(6), 898-920.

Sikora, J., \& Saha, L. J. (2009). Gender and professional career plans of high school students in comparative perspective. Educational Research and Evaluation, 15(4), $387-405$.

Sikora, J., \& Saha, L. J. (2010). Lost talent? The occupational expectations and attainments of young Australians. Adelaide: National Centre for Vocational Education Research.

Suda, Z. (1979). Universal growth of education aspirations and the over-qualification problem: Conclusions from a comparative data analysis. European Journal of Education, 14, $113-164$.

Turner, R. (1964). The social context of ambition. San Francisco: Chandler Publishing Company. UNESCO. (2007). Education for all global monitoring report 2008. Oxford: UNESCO Publishing.

UNESCO (2010). UNESCO's institute for statistics. Available at http://data.un.org/. Retrieved on August 1, 2010.

White, P. (2007). Education and career choice: A new model of decision making. New York: Palgrave.

Wiseman, A. W., \& Baker, D. P. (2006). The symbiotic relationship between empirical comparative research on education and neo-institutional theory. In: D. P. Baker \& A. W. Wiseman (Eds), The impact of comparative education research on institutional theory (pp. 1-26). Amsterdam, Oxford: Elsevier, JAI.

World Bank (2010). World development indicators. Available at http://ddp-ext.worldbank.org. Retrieved on August 1, 2010. 


\section{APPENDIX. DETAILS OF MEASUREMENT- COUNTRY CHARACTERISTICS}

Whenever possible, the reference year for all country-level statistics is 2004. If data for 2004 were not available, we used the data for 2005. If there were also no data for 2005 , we used the point in time that was closest to 2004 .

The information about reception of aid for education in 2004 was obtained from UNESCO's "Education for All Global Monitoring Report 2008" (UNESCO, 2007, p. 382). Countries which were listed as recipients of aid were coded as 1 and all the other countries were coded as 0 .

Secondary school net enrolment rate was sourced from UNESCO's Institute for Statistics online database (UNESCO, 2010). Whenever possible, we used 2004 as the reference year but the figure for Canada is the 2001 figure. Data for the Czech Republic, Austria, Taiwan, Latvia, Russian Federation, and Slovak Republic were obtained from the UNICEF website (http://www.unicef.org/infobycountry) or from country-specific national statistical offices.

Number of school types or distinct school programs available to 15-yearolds was obtained from OECD's "Education at a Glance" (OECD, 2005b, p. 400). For European countries, for which the information was not available in this publication, the information from Eurybase-Descriptions of Education Systems http://eacea.ec.europa.eu/education/eurydice/index en.php was used. Finally, for those countries for which the information was not available in either source, we used country-specific descriptions of educational systems, the details of which are available upon request.

Percentage of 25 to 34 year olds with tertiary education was obtained from the International Labor Office's LABORSTA online Labor Statistics Database (International Labor Organization, 2010). For Colombia, Jordan, Spain, Thailand, Tunisia, and Uruguay, we used the 2002 data from Table A3.3 in "Education at a Glance" (OECD, 2004).

Index of GDP per capita and service employment ratio to USA was created in three steps. First, the data for 2004 for GDP per capita in constant dollars and for the proportion of labor force employed in services were obtained from World Development Indicators online (World Bank, 2010). The figures for both indicators for each country were then divided by the relevant USA figures, so that the USA value on both GDP per capita and the proportion of labor force employed in the service sector equalled 1 . Finally, ratios for each country were averaged resulting in the index value. 
The values of the GINI coefficients for each country were obtained from the World Development Indicators online (World Bank, 2010). Where data for 2004 were unavailable, we used data from the closest point in time and, in several cases we used the data from national statistical offices, the details of which are available upon request.

Growth of the service sector 1997-2004 was estimated for each country based on the data from World Development Indicators online (World Bank, 2010). For Colombia, Taiwan, and Tunisia, we used the information from their national statistical offices. 
Table A1. Mean Occupational Expectations and Missing Data in 50 Countries in 2006.

\begin{tabular}{|c|c|c|c|c|c|c|}
\hline \multirow[t]{2}{*}{ Nations } & \multicolumn{2}{|c|}{ ISEI 2006} & \multirow{2}{*}{$\begin{array}{c}\text { Total Invalid } \\
\text { Answers } \\
(\%)\end{array}$} & \multirow{2}{*}{$\begin{array}{l}\text { Uncodable } \\
\text { answers } \\
(\%)\end{array}$} & \multirow{2}{*}{$\begin{array}{c}\text { Missing } \\
(\%)\end{array}$} & \multirow{2}{*}{$\begin{array}{c}\text { Missing and } \\
\text { Uncodable } \\
\text { Answers (\%) } \\
\text { - Top } 30 \% \\
\text { Students }\end{array}$} \\
\hline & Mean & $N$ & & & & \\
\hline Azerbaijan & 68.7 & 3,346 & 35 & 3 & 32 & 24 \\
\hline Argentina & 64.0 & 3,663 & 20 & 8 & 12 & 9 \\
\hline Australia & 56.9 & 114,616 & 19 & 8 & 11 & 13 \\
\hline Austria & 51.9 & 3,291 & 28 & 18 & 10 & 31 \\
\hline Belgium & 55.3 & 6,995 & 23 & 11 & 12 & 21 \\
\hline Brazil & 66.2 & 7,477 & 19 & 10 & 9 & 19 \\
\hline Bulgaria & 65.4 & 3,150 & 30 & 20 & 10 & 28 \\
\hline Canada & 61.2 & 18,466 & 18 & 13 & 5 & 13 \\
\hline Chile & 64.1 & 4,217 & 16 & 10 & 6 & 14 \\
\hline Colombia & 69.1 & 4,040 & 10 & 2 & 8 & 7 \\
\hline Croatia & 55.0 & 3,426 & 34 & 22 & 12 & 34 \\
\hline Czech Republic & 52.5 & 3,999 & 27 & 18 & 9 & 25 \\
\hline Denmark & 54.5 & 3,510 & 43 & 9 & 33 & 25 \\
\hline Estonia & 57.3 & 3,597 & 26 & 12 & 14 & 21 \\
\hline Finland & 51.3 & 3,522 & 24 & 11 & 13 & 25 \\
\hline France & 54.9 & 3,565 & 26 & 12 & 13 & 20 \\
\hline Germany & 52.1 & 3,237 & 32 & 17 & 15 & 25 \\
\hline Greece & 61.0 & 3,566 & 18 & 7 & 10 & 18 \\
\hline Hong Kong & 58.5 & 3,820 & 24 & 14 & 10 & 14 \\
\hline Hungary & 53.3 & 3,047 & 23 & 12 & 11 & 26 \\
\hline Iceland & 60.4 & 2,899 & 24 & 11 & 13 & 17 \\
\hline Indonesia & 61.5 & 7,905 & 25 & 9 & 17 & 22 \\
\hline Ireland & 57.6 & 3,797 & 17 & 10 & 7 & 14 \\
\hline Italy & 59.9 & 18,357 & 17 & 9 & 7 & 14 \\
\hline Japan & 55.1 & 3,908 & 38 & 20 & 18 & 25 \\
\hline Jordan & 67.5 & 4,761 & 27 & 5 & 22 & 13 \\
\hline Korea (ROK) & 60.8 & 4,773 & 11 & 7 & 4 & 4 \\
\hline Kyrgyzstan & 67.2 & 3,780 & 36 & 5 & 31 & 21 \\
\hline Latvia & 57.9 & 3,517 & 35 & 20 & 14 & 17 \\
\hline Lithuania & 60.3 & 3,496 & 26 & 14 & 12 & 18 \\
\hline Mexico & 67.4 & 24,124 & 24 & 10 & 14 & 14 \\
\hline Netherlands & 53.9 & 4,229 & 14 & 11 & 3 & 15 \\
\hline New Zealand & 57.6 & 3,695 & 22 & 10 & 12 & 19 \\
\hline Norway & 56.0 & 3,342 & 26 & 13 & 13 & 23 \\
\hline Poland & 58.9 & 4,385 & 24 & 10 & 14 & 11 \\
\hline Portugal & 61.7 & 4,052 & 19 & 12 & 7 & 20 \\
\hline Romania & 58.3 & 4,549 & 11 & 7 & 4 & 5 \\
\hline Russia & 62.6 & 4,354 & 25 & 13 & 12 & 19 \\
\hline
\end{tabular}


Table A1. (Continued)

\begin{tabular}{|c|c|c|c|c|c|c|}
\hline \multirow[t]{2}{*}{ Nations } & \multicolumn{2}{|c|}{ ISEI 2006} & \multirow{2}{*}{$\begin{array}{c}\text { Total Invalid } \\
\text { Answers } \\
(\%)\end{array}$} & \multirow{2}{*}{$\begin{array}{l}\text { Uncodable } \\
\text { answers } \\
(\%)\end{array}$} & \multirow{2}{*}{$\begin{array}{c}\text { Missing } \\
(\%)\end{array}$} & \multirow{2}{*}{$\begin{array}{c}\text { Missing and } \\
\text { Uncodable } \\
\text { Answers (\%) } \\
\text { - Top 30\% } \\
\text { Students }\end{array}$} \\
\hline & Mean & $N$ & & & & \\
\hline Slovakia & 56.8 & 3,538 & 28 & 20 & 8 & 17 \\
\hline Slovenia & 59.2 & 5,026 & 24 & 8 & 16 & 20 \\
\hline Spain & 60.2 & 14,447 & 25 & 9 & 16 & 16 \\
\hline Sweden & 53.4 & 3,587 & 20 & 14 & 7 & 21 \\
\hline Switzerland & 49.8 & 9,793 & 23 & 14 & 9 & 19 \\
\hline Taiwan & 58.4 & 7,179 & 19 & 13 & 5 & 12 \\
\hline Thailand & 60.3 & 4,147 & 24 & 11 & 14 & 16 \\
\hline Tunisia & 68.6 & 3,897 & 16 & 3 & 13 & 8 \\
\hline Turkey & 66.3 & 3,999 & 19 & 0 & 19 & 10 \\
\hline United Kingdom & 56.3 & 11,229 & 34 & 30 & 4 & 13 \\
\hline United States & 62.8 & 4,665 & 20 & 7 & 13 & 17 \\
\hline Uruguay & 65.3 & 3,867 & 20 & 12 & 8 & 14 \\
\hline$(N)$ & & 389,847 & & & & \\
\hline
\end{tabular}

Table A2. Correlations Between Country Characteristics.

\begin{tabular}{|c|c|c|c|c|c|c|c|c|c|}
\hline 2004 & 1. & 2. & 3. & 4. & 5. & 6. & 7. & 8. & 9. \\
\hline $\begin{array}{l}\text { 1. Country receives } \\
\text { education-related aid }\end{array}$ & 1 & & & & & & & & \\
\hline $\begin{array}{l}\text { 2. Secondary school net } \\
\text { enrolment rate }\end{array}$ & $-0.61^{* *}$ & 1 & & & & & & & \\
\hline $\begin{array}{l}\text { 3. Number of school } \\
\text { types available to } \\
15 \text {-year-olds }\end{array}$ & 0.08 & $-0.18^{* *}$ & 1 & & & & & & \\
\hline $\begin{array}{l}\text { 4. Percentage of } \\
\text { 25-34-year-olds with } \\
\text { tertiary education }\end{array}$ & $-0.44^{* *}$ & $0.61^{* *}$ & -0.18 & 1 & & & & & \\
\hline $\begin{array}{l}\text { 5. Percent of labor force } \\
\text { employed in services }\end{array}$ & $-0.35^{* *}$ & $0.41^{* *}$ & -0.18 & $0.29^{*}$ & 1 & & & & \\
\hline 6. GDP per capita & $-0.56^{* *}$ & $0.47^{* *}$ & -0.07 & $0.45^{* *}$ & $0.72^{* *}$ & 1 & & & \\
\hline $\begin{array}{l}\text { 7. Index of GDP } \\
\text { and service } \\
\text { employment }\end{array}$ & $-0.53^{* *}$ & $0.47^{* *}$ & -0.11 & $0.43^{* *}$ & $0.86^{* *}$ & $0.98^{* *}$ & 1. & & \\
\hline 8. Gini coefficient & $0.53^{* *}$ & $-0.60^{* *}$ & -0.01 & $-0.39^{* *}$ & * -0.07 & $-0.41^{* *}$ & $-0.32 * *$ & 1 & \\
\hline $\begin{array}{l}\text { 9. Growth of the } \\
\text { service sector } \\
1997-2004\end{array}$ & -0.15 & 0.08 & 0.00 & 0.22 & -0.16 & 0.03 & -0.03 & -0.09 & 1.00 \\
\hline
\end{tabular}

\footnotetext{
** Statistically different from zero at $p=0.01,{ }^{*}$ statistically different from zero at $p=0.05$.
} 